\title{
Prevention of bronchial hyperreactivity in a rat model of precapillary pulmonary hypertension
}

\author{
Walid Habre ${ }^{1}$, Gergely Albu², Tibor Z Janosi², Fabienne Fontao², Britta S von Ungern-Sternberg ${ }^{2}$, \\ Maurice Beghetti ${ }^{3}$ and Ferenc Petak ${ }^{4 *}$
}

\begin{abstract}
Background: The development of bronchial hyperreactivity (BHR) subsequent to precapillary pulmonary hypertension (PHT) was prevented by acting on the major signalling pathways (endothelin, nitric oxide, vasoactive intestine peptide (VIP) and prostacyclin) involved in the control of the pulmonary vascular and bronchial tones.

Methods: Five groups of rats underwent surgery to prepare an aorta-caval shunt (ACS) to induce sustained precapillary PHT for 4 weeks. During this period, no treatment was applied in one group (ACS controls), while the other groups were pretreated with VIP, iloprost, tezosentan via an intraperitoneally implemented osmotic pump, or by orally administered sildenafil. An additional group underwent sham surgery. Four weeks later, the lung responsiveness to increasing doses of an intravenous infusion of methacholine $(2,4,812$ and $24 \mu \mathrm{g} / \mathrm{kg} / \mathrm{min})$ was determined by using the forced oscillation technique to assess the airway resistance (Raw).
\end{abstract}

Results: BHR developed in the untreated rats, as reflected by a significant decrease in $\mathrm{ED}_{50}$, the equivalent dose of methacholine required to cause a 50\% increase in Raw. All drugs tested prevented the development of BHR, iloprost being the most effective in reducing both the systolic pulmonary arterial pressure ( $\mathrm{Ppa} ; 28 \%, \mathrm{p}=0.035$ ) and BHR ( $E D_{50}=9.9 \pm 1.7$ vs. $43 \pm 11 \mu \mathrm{g} / \mathrm{kg}$ in ACS control and iloprost-treated rats, respectively, $\mathrm{p}=0.008$ ). Significant correlations were found between the levels of $\mathrm{Ppa}$ and $\mathrm{ED}_{50}(R=-0.59, \mathrm{p}=0.016)$, indicating that mechanical interdependence is primarily responsible for the development of BHR.

Conclusions: The efficiency of such treatment demonstrates that re-establishment of the balance of constrictor/ dilator mediators via various signalling pathways involved in PHT is of potential benefit for the avoidance of the development of BHR.

\section{Background}

There has recently been substantial progress in the development of new therapeutic strategies for the management of patients with pulmonary hypertension (PHT) [1-5]. The improvements are based on a better understanding of the mechanisms involved in the development of PHT. These treatment strategies are based on the recognition that a key role is played in the modulation of the tone of the smooth muscle cells in the pulmonary vasculature by an imbalance between the vasoactive constrictor and proliferative mediators (endothelin-1 (ET-1), substance $\mathrm{P}$ and angiotensin II) and the vasorelaxing and antiproliferative mediators (adrenomedullin, vasoactive

\footnotetext{
* Correspondence: petak@dmi.szote.u-szeged.hu

${ }^{4}$ Department of Medical Physics and Informatics, University of Szeged,

9 Koranyi fasor, H-6720, Szeged, Hungary

Full list of author information is available at the end of the article
}

intestinal peptide (VIP), prostacyclins (PCs) and nitric oxide (NO)) [6]. The bronchoactive potential of these peptides has been recognized as the major cause of the lung function deterioration [1,2,7-10].

We earlier reported a lung function impairment in a reproducible model of precapillary $\mathrm{PHT}$ following the creation of a shunt between the abdominal aorta and the vena cava in rats [11]. We also demonstrated that precapillary PHT leads to the development of bronchial hyperresponsiveness (BHR) to methacholine subsequent to the altered mechanical interdependence between the pulmonary vasculature and the respiratory tract. Although novel strategies are available for the treatment of pulmonary vascular diseases, no studies have yet characterized how the adverse pulmonary consequences of these clinically important pulmonary vascular abnormalities can be prevented. Accordingly, in the present study we set out to 
explore the efficiency of treatment strategies designed to prevent the adverse changes in the lung function and bronchial responsiveness by acting on the imbalance between the vasoactive constrictor-proliferative and vasorelaxing-antiproliferative mediators.

\section{Methods}

\section{Animal preparations}

The experimental protocol was approved by the Experimental Ethics Committee of the University of Geneva and the Animal Welfare Committee of the Canton of Geneva. Fifty-six adult male Sprague-Dawley rats (weighing 312-382 g) were anaesthetized by an intraperitoneal injection of pentobarbital $(70-90 \mathrm{mg} / \mathrm{kg}$ of a $50 \mathrm{mg} / \mathrm{ml}$ solution). Tracheal intubation was achieved with a polyethylene cannula (16-gauge, Braun, Melsungen, Germany) and the rats were mechanically ventilated with a tidal volume of $7 \mathrm{ml} / \mathrm{kg}$ body weight, a positive end-expiratory pressure of $2.5 \mathrm{~cm} \mathrm{H}_{2} \mathrm{O}$, and a respiratory rate of 70-80/min (model 683, Harvard Apparatus Co Inc., South Natick, MA, USA). Anesthesia was maintained with pentobarbital administered intravenously every $40 \mathrm{~min}(5 \mathrm{mg} / \mathrm{kg})$. The femoral vein was cannulated for drug delivery. The airway pressure, ECG and rectal temperature were monitored continuously by a data collection and acquisition system (Biopac, Santa Barbara, CA, USA). Fentanyl was administered intravenously $(15 \mu \mathrm{g} / \mathrm{kg})$ to ensure adequate analgesia before the administration of pancuronium intravenously $(0.4 \mathrm{mg} / \mathrm{kg})$ to facilitate forced oscillatory measurements. To ensure adequate postoperative analgesia, buprenorphine $(0.5 \mathrm{mg} / \mathrm{kg})$ was injected subcutaneously before emergence from anesthesia and again $18 \mathrm{~h}$ after surgery.

\section{Induction of precapillary pulmonary hypertension}

The surgical induction of precapillary PHT was performed as described in detail previously [11-13]. Briefly, a midline abdominal incision was made in a sterile manner and the infra-renal portions of the abdominal aorta and inferior vena cava were exposed at the site where the two vessels share a common fascia. An aorto-caval shunt (ACS) was then prepared by introducing a needle between the two vessels, followed by application of an aortic adventitial suture. In the rats that received various treatments (see below), an osmotic intraperitoneal pump (Alzet model 2ML4, Alza corporation, Palo Alto, USA) was implanted intraperitoneally into the lower abdomen in order to allow continuous delivery of the different drug medications during 4 weeks. The abdomen was closed in a sterile manner and a long-acting local anesthetic (bupivacaïne $0.25 \%, 0.8-1.2 \mathrm{ml}$ ) was infiltrated around the surgical wounds.

\section{Treatments, protocol groups}

After creation of the ACS, the animals were randomized to be included in one or other of the groups detailed below (Figure 1). The route of administration of the treatment agents and the doses were chosen on the basis of their pharmacokinetic properties and the manufacturers' recommendations.

\section{Group CC $(n=13)$}

These control rats underwent the surgical procedure as detailed above, but without preparation of the ACS. A subgroup $(n=7)$ of these animals underwent sham surgery and implementation of an intraperitoneal pump for the continuous delivery of normal saline in the 4-week period, while the remaining rats were not implanted with the pump $(n=6)$. Since there was no difference between these sham subgroups in the data relating to any of the parameters measuring hemodynamics or respiratory mechanics, their data were pooled for further analyses.

Group CS $(n=10)$

An ACS was prepared in these animals, but no subsequent drug treatment was applied.

\section{Group VIP $(n=8)$}

To test the VIP pathway in affecting PHT and the subsequent BHR, rats with an ACS received VIP $150 \mu \mathrm{g} / \mathrm{kg} /$ day, administered via the intraperitoneal pump $(2.5 \mu \mathrm{l} / \mathrm{h})$ for 4 weeks.

Group ILO $(n=10)$

To study the PC pathway in influencing PHT and the subsequent BHR, rats with ACS received iloprost $80 \mu \mathrm{g} /$ $\mathrm{kg}$ for 4 weeks via the intraperitoneal pump $(5 \mu \mathrm{l} / \mathrm{h})$.

Group SIL $(n=7)$

To investigate the role of NO in the precapillary PHT and the subsequent BHR, ACS preparation was followed by a 4-week treatment with sildenafil administered orally ( $25 \mathrm{mg} /$ day dissolved in $1.5 \mathrm{ml}$ saline).

Group TEZ $(n=8)$

To explore how the ET-1-related mechanisms affect the precapillary PHT and the subsequent BHR, rats with an ACS were treated for 4 weeks with the combined $\mathrm{ET}_{\mathrm{A}}-\mathrm{ET}_{\mathrm{B}}$ receptor blocker tezosentan $(10 \mathrm{mg} / \mathrm{kg} /$ day $)$ administered via an intraperitoneal pump $(2.5 \mu \mathrm{l} / \mathrm{h})$.

\section{Measurements of end-expiratory lung volume (EELV)}

EELV measurements were accomplished in all groups with a body plethysmograph, as detailed previously [14]. Briefly, the trachea was occluded at end expiration until 3 or 4 spontaneous inspiratory efforts had been generated by the animal in the closed box. The changes in tracheal pressure and plethysmograph box pressure during these manoeuvres were recorded, and EELV was calculated by applying Boyle's law to the relationship between the tracheal pressure and the box pressure after correcting for the box impedance [15]. 


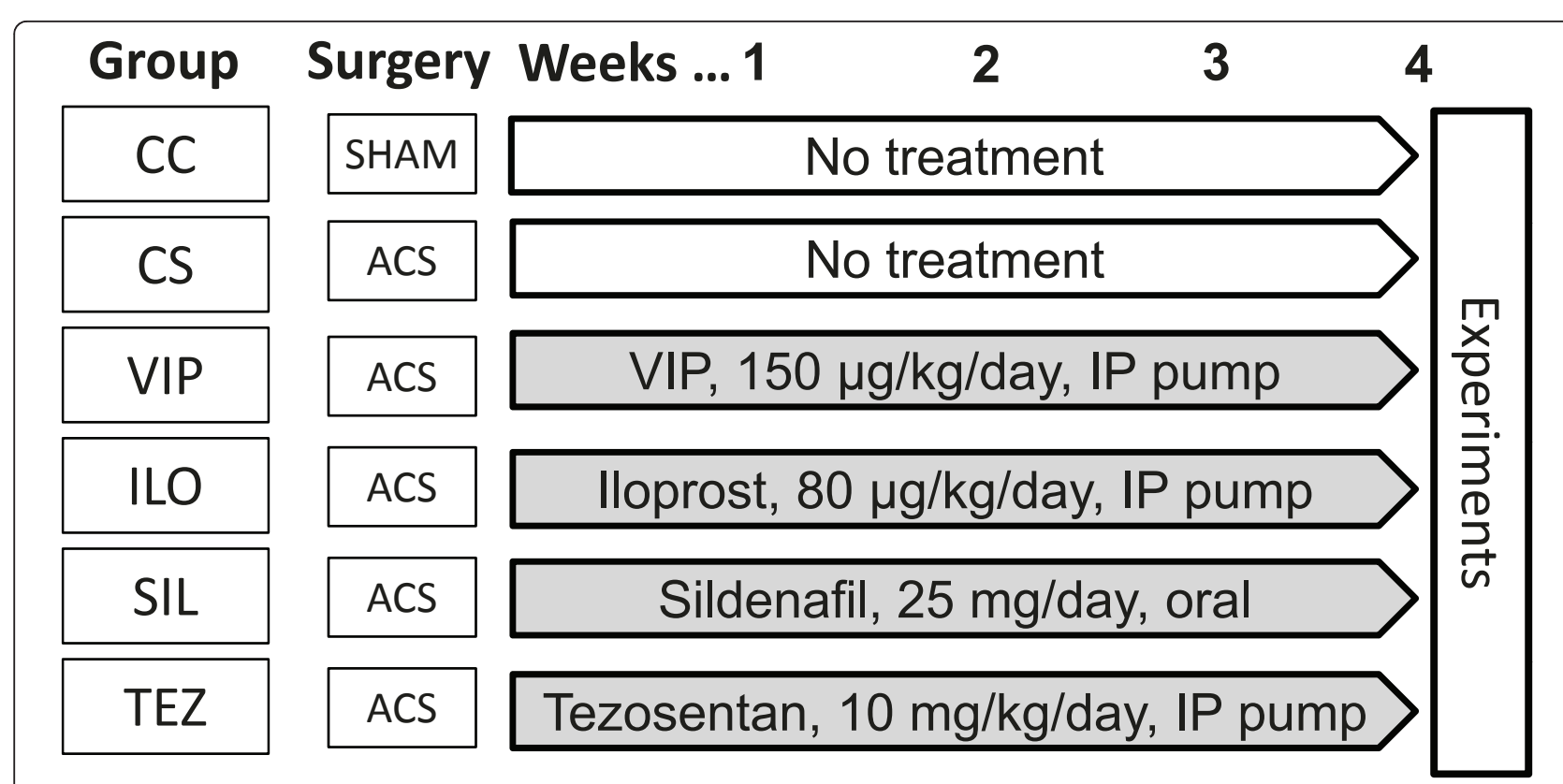

Figure 1 Experimental protocol. Zrs: forced oscillatory recordings of the respiratory input impedance. MCh: methacholine.

\section{Forced oscillatory measurements}

The contributions of the airway and tissue mechanical properties to the total respiratory resistance were estimated by the forced oscillation technique by measuring the mechanical impedance of the respiratory system (Zrs), as described in detail previously [16,17]. Briefly, the tracheal cannula was connected from the respirator to a loudspeaker-in-box system at end-expiration. Zrs was measured with the wave-tube technique by introducing pseudorandom forced oscillations at frequencies between 0.5 and $21 \mathrm{~Hz}$ at end-expiration. Two identical pressure transducers (Model 33NA002D, ICSensors, Malpitas, CA, USA) were used to measure the lateral pressures at the loudspeaker and at the tracheal end of the wave-tube, and Zrs was calculated as the load impedance of the wave-tube by using fast Fourier transformation [16].

To separate the airway and tissue mechanics, a model containing a frequency-independent resistance (Raw) and inertance (Iaw) in series with a constant-phase tissue model [18] including tissue damping (G) and elastance $(\mathrm{H})$ was fitted to the Zrs spectra by minimizing the differences between the measured and modelled impedance values:

$$
\mathrm{Zrs}=\mathrm{Raw}+\mathrm{j} \omega \mathrm{Iaw}+(\mathrm{G}-\mathrm{jH}) / \omega^{\alpha}
$$

where $\mathrm{j}$ is the imaginary unit, is the angular frequency (2f) and $=2 / \arctan (\mathrm{H} / \mathrm{G})$. When this model is fitted to Zrs spectra, the parameter Raw is primarily related to the overall airway geometry, as the contribution of the chest wall to the frequency-independent Newtonian resistance is minor [19]. Similarly, the inertia of the gas in the airways predominates in the parameter Iaw [19].

\section{Measurement of pulmonary haemodynamics}

The pulmonary arterial pressure (Ppa) was measured by introducing a small catheter (polyethylene tubing, ID $0.88 \mathrm{~mm}$, Portex, Hythe, GB) into the pulmonary artery via the jugular vein beforethe animals were sacrificed. This measurement was technically acceptable only in subgroups of the main study groups, involving 7, 10, 4, 5, 2 and 6 rats in Groups CC, CS, VIP, ILO, SIL and TEZ, respectively.

\section{Measurement protocol and bronchoprovocation challenges}

Four weeks following the surgical preparation of ACS, the rats were again anaesthetized and intubated, and the experimental protocol was performed. EELV was first measured while the rats were breathing spontaneously. A femoral vein was then cannulated for drug delivery. When stable hemodynamic and respiratory mechanical conditions had been reached, a set of Zrs data including 4-6 6-s long recordings was recorded under the baseline conditions. Increasing doses of iv methacholine $(\mathrm{MCh})$ were then administered at doses of 2, 4, 8, 12 and $24 \mu \mathrm{g} / \mathrm{kg} / \mathrm{min}$, and at each infusion rate 3-5 Zrs recordings were made during the development of steady-state bronchoconstriction (usually 3-5 min after the onset of $\mathrm{MCh}$ ). The equivalent dose causing a $50 \%$ increase in Raw $\left(\mathrm{ED}_{50}\right)$ was calculated in each rat by linear 
interpolation. Following these measurements, Ppa was measured as described above.

\section{Statistical analyses}

The scatters in the parameters were expressed by the SE values. The Kolmogorov-Smirnov test was used to test data for normality. One-way analysis of variances (ANOVA) was performed to test significant differences in the parameters among the groups. Two-way repeated measures ANOVA, with variables of treatment (i.e. the protocol groups) and MCh dose, was used to evaluate the effects of the various types of medication on the precapillary PHT and subsequent lung responsiveness to the constrictor challenge. Pairwise comparisons were performed by means of Student-Newman-Keuls multiple comparison procedures. Pearson correlation test was used to assess the strength of associations between variables. Statistical tests were carried out with the significance level set at $\mathrm{p}<0.05$.

\section{Results}

There was no significant difference in body weight among the protocol groups either at the beginning of the study (ranging from $340 \pm 9 \mathrm{~g}$ to $360 \pm 4 \mathrm{~g}, \mathrm{p}=$ 0.11 ) or at the time of the experiments 4 weeks later (ranging from $413 \pm 14 \mathrm{~g}$ to $454 \pm 12 \mathrm{~g}, \mathrm{p}=0.1$ )

Figure 2 demonstrates the systolic and diastolic values of Ppa for the various groups. Preparation of the ACS led to a significant increase in systolic Ppa $(p=0.036)$. This PHT was significantly inhibited only by iloprost ( $p=0.035)$; none of the other treatments affected the alteration in Ppa. No change in the diastolic Ppa was detected $(\mathrm{p}=0.15)$.

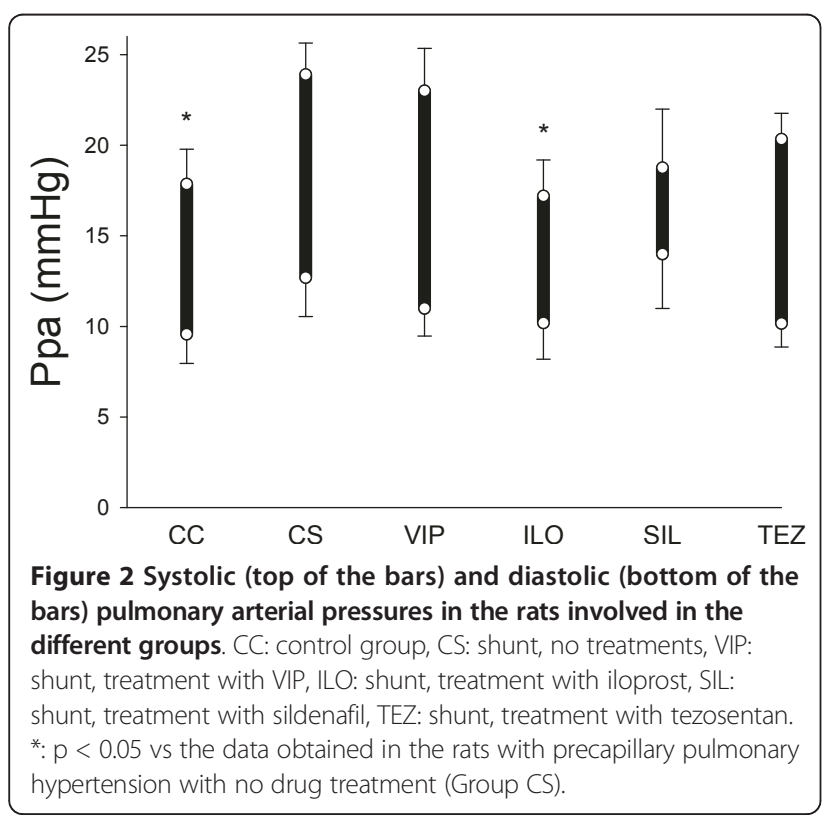

The baseline in the EELV and the forced oscillatory parameters in the different groups are displayed in Figure 3. ACS preparation and subsequent treatments did not affect the basal lung volume $(p=0.22)$, the basal Raw ( $\mathrm{p}=0.28)$ or the respiratory tissue parameters $(\mathrm{p}=0.45)$.

Figure 4 depicts the airway responses to $\mathrm{MCh}$ challenges in the groups. MCh induced a dose-dependent bronchoconstriction of various magnitude in all groups. ACS preparation led to the development of BHR, as illustrated by the significant upward shift in the dose response-curve. Each of the drug treatments exerted a protective effect against this hyperresponsiveness to MCh. The MCh-induced changes in $\mathrm{G}$ and $\mathrm{H}$ were far more moderate and did not exhibit a statistically significant difference among the groups $(\mathrm{p}=0.45$, and $\mathrm{p}=$ 0.26 for $G$ and $H$, respectively; Table 1 ).

To illustrate the effects of the various treatments on the airway responses to $\mathrm{MCh}$, the $\mathrm{ED}_{50}$ values are compared in Figure 5. The BHR induced by generating a precapillary PHT by ACS was manifested in a significant decrease in $\mathrm{ED}_{50}$ in Group CS relative to that in Group $\mathrm{CC}(\mathrm{p}=0.008)$. All of the treatments exerted a significant protective potential, leading in Groups VIP and TEZ an airway responsiveness similar to that observed in the sham operated rats (Group CC). This parameter revealed even overprotection of the airway responsiveness to MCh in Group ILO and Group SIL.

The relationships between the systolic Ppa and ED $_{50}$ is depicted in Figure 6. These parameters relating to the pulmonary haemodynamics and lung responsiveness exhibited a statistically significant correlation for the entire study population $(\mathrm{R}=-0.59, \mathrm{p}=0.016)$ and were variable for the individual study groups with closest correlation being observed in Group CS $(R=-0.6)$ and the weakest in rats with no intervention (Group $C$, $\mathrm{R}=0.1)$.

\section{Discussion}

Various treatment strategies applied against PHT act on the imbalance between the vasoactive constrictor-proliferative and vasorelaxing-antiproliferative mediators. In the present study, we investigated whether these treatments provide protection against the enhanced airway responsiveness observed in the presence of precapillary PHT. The results obtained in this well-validated animal model of BHR originating from precapillary PHT induced by ACS preparation demonstrate that all the treatment modes studied, including the action on the VIP, PC, NO and ET-1 pathways, exhibited a beneficial profile in preventing the development of BHR. Pooling of all the data points obtained from the groups revealed that the systolic Ppa level and the magnitude of the lung responsiveness were associated. 

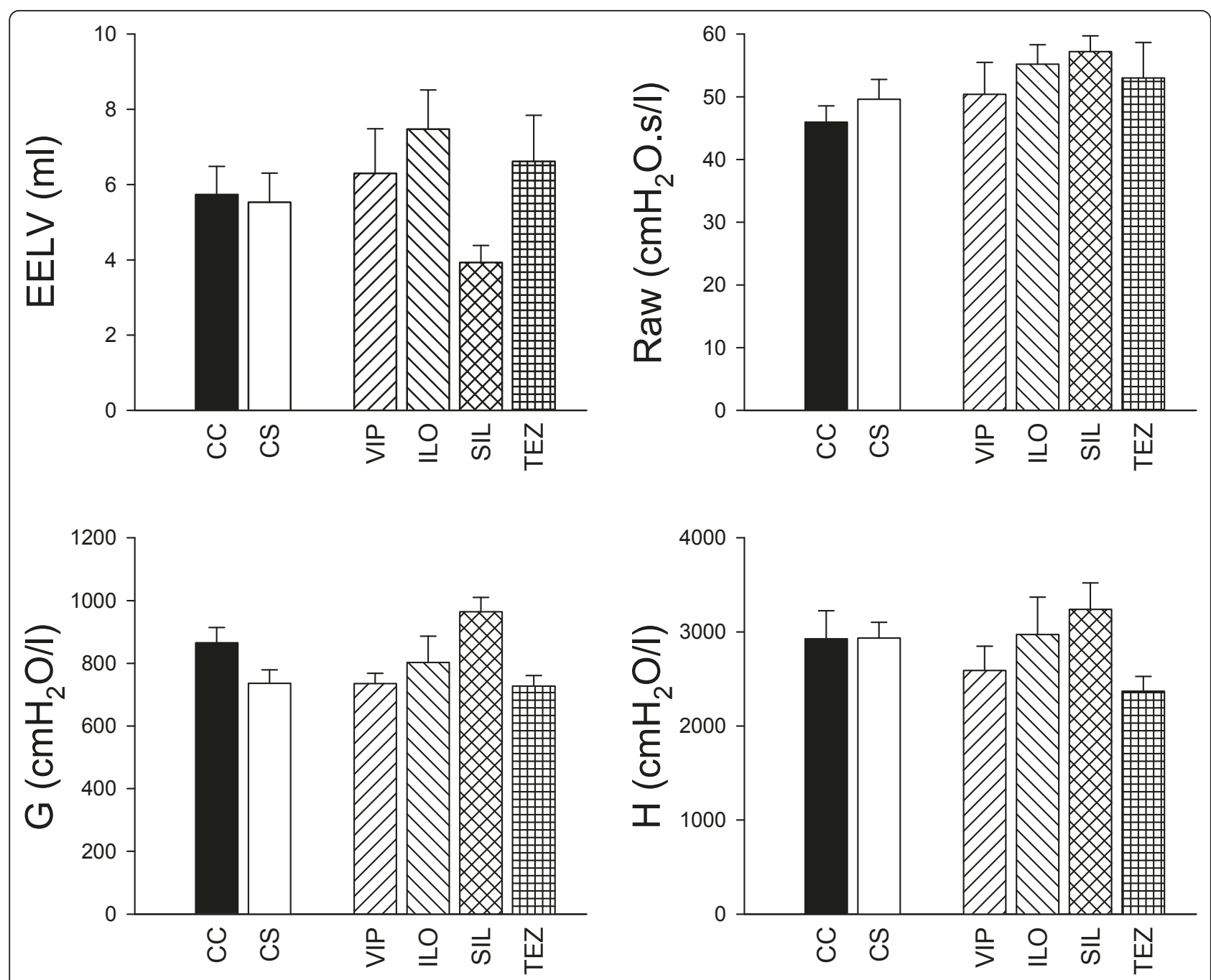

Figure 3 The baseline end-expiratory lung volume (EELV), airway resistance (Raw), respiratory tissue damping (G) and elastance (H) data obtained in the different groups. CC: control group, CS: shunt, no treatments, VIP: shunt, treatment with VIP, ILO: shunt, treatment with iloprost, SIL: shunt, treatment with sildenafil, TEZ: shunt, treatment with tezosentan.

It was earlier reported [11] that the creation of an ACS led to precapillary PHT, which was associated with enhanced airway responsiveness to $\mathrm{MCh}$. This experimental model has been extensively validated previously both by ourselves and by other research groups, and has been proved to provide an increased pulmonary blood flow leading to PHT [11-13,20]. Precise measurement of the pulmonary haemodynamics in rats was complicated by the small size of the animal and the lack of cathetertip balloon, which normally helps to introduce to the pulmonary artery. Due to this technical difficulty, technically acceptable Ppa recordings were possible only in about two-third of the rats. According to literature $[11,13,20]$, we also noted an elevated systolic Ppa in the rats in Group CS, confirming the validity of the experimental model for investigation of the pulmonary consequences of chronic precapillary PHT. It is noteworthy, however, that the model applied here mimics clinical conditions encountered in patients with left-to-right shunts and increased pulmonary blood flow, and the results may not be extrapolated to other forms of PHT. The altered mechanical interdependence between the pulmonary vasculature and the respiratory tract is responsible for the BHR in this experimental model, thus the effects of the applied treatment strategies in the present study are valid for this pulmonary haemodynamical abnormality.

In agreement with previous data [11], we did not observe statistically significant changes in the baseline values of the respiratory mechanical parameters following sustained precapillary PHT. However, normalization of the Raw to the lung volume revealed a statistically significant increase in this specific Raw $(\mathrm{p}<0.006)$, which is in harmony with the earlier results that ACS causes a detectable elevation only in the corrected 


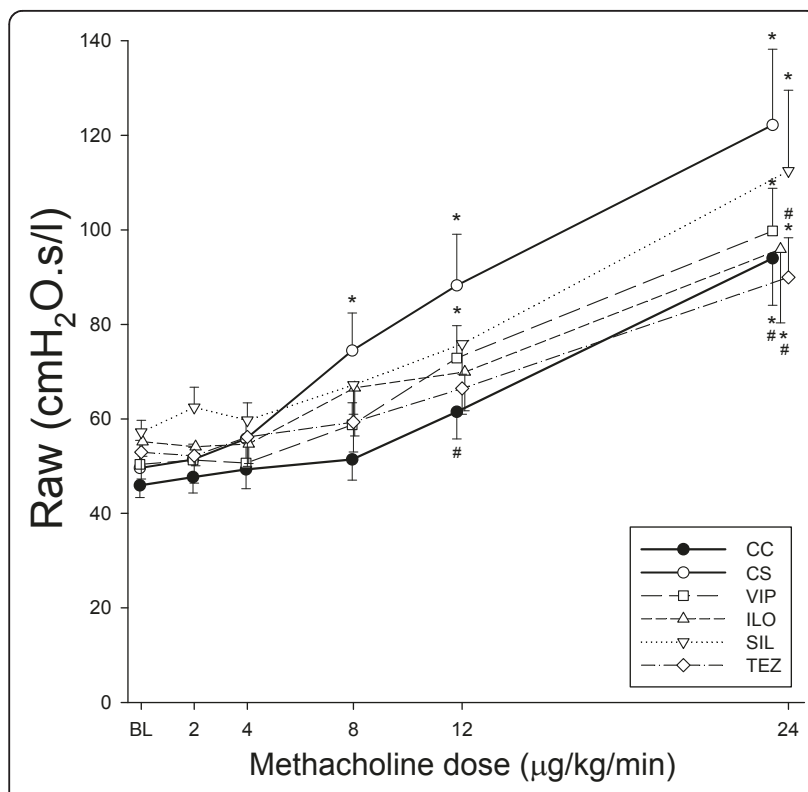

Figure 4 Methacholine-induced changes in airway resistance (Raw) in the different groups. CC: control group, CS: shunt, no treatments, VIP: shunt, treatment with VIP, ILO: shunt, treatment with iloprost, SIL: shunt, treatment with sildenafil, TEZ: shunt, treatment with tezosentan. ${ }^{*}: p<0.05$ vs the value obtained under baseline conditions (BL) within a group; \#: $p<0.05$ vs. the data obtained in the rats with precapillary pulmonary hypertension without drug treatment (Group CS).

baseline Raw. Accordingly, it can be anticipated that the experimental model applied here reflects the major features of the respiratory mechanical changes encountered under baseline conditions in patients with chronic precapillary PHT.

The three major mechanisms involved in the development of PHT are the PC, the ET and NO pathways. The pathological changes in these pathways are manifested by an imbalance of the mediators with vasodilation or vasoconstriction potential. These pathways have also been implicated in the regulation of the airway smooth muscle tone $[8,10,21,22]$. Thus, we restored an optimum balance between the constrictor/dilator mediators through selective targeting of these mechanisms to characterize whether these treatment strategies affect lung responsiveness.

Iloprost is a PC analogue and a potent pulmonary vasodilator that exerts its effect through the activation of cyclic adenosine monophosphate (cAMP) [2]. Since the molecule has a short half-life (approximately $20 \mathrm{~min}$ ), we followed the common strategy of delivering it via a continuous infusion. In agreement with previous findings, this treatment strategy effectively inhibited the PHT $[23,24]$. Over and above this well-established beneficial pulmonary vascular effect, our study is the first to demonstrate that this pharmacotherapeutic management is associated with complete prevention of the development of BHR.

Another essential pathway involved in the pathogenesis of PHT is related to a dysfunction in the key pulmonary vasodilator NO [25]. Enhancement of the NO-mediated effects by phosphodiesterase 5 inhibitors such as sildenafil has therefore been proposed as an effective mode of treatment against PHT $[9,26]$. NO is known to exert a potent bronchodilation effect [27], and its overexpression leads to a direct relaxing effect on the airway smooth muscle. Since excessive NO in the lungs has been shown to inhibit MCh-induced bronchoconstriction [28], this mechanism is probably involved in the complete prevention of BHR in Group SIL in the present study.

The rationale of testing the ability of tezosentan, a dual ET-1 receptor antagonist, to prevent BHR emerged from the crucial involvement of ET-1 in the pathogenesis of PHT [25]. ET-1 exerts its regulatory effect on the pulmonary vascular and bronchial tone via two receptor subtypes $\left(\mathrm{ET}_{\mathrm{A}}\right.$ and $\left.\mathrm{ET}_{\mathrm{B}}\right)$. The roles of these receptor subtypes on the pulmonary vascular and bronchial tone are dissociated, with $\mathrm{ET}_{\mathrm{A}}$ stimulation leading to vasoconstriction and bronchodilation $[10,29]$, while activation of $\mathrm{ET}_{\mathrm{B}}$ receptors results in the liberation of vasodilator mediators with a concomitant bronchodilation potential $[10,30]$. The opposing effects of $\mathrm{ET}_{\mathrm{A}}$ and $\mathrm{ET}_{\mathrm{B}}$ following dual receptor blockade may therefore have resulted in the lack of significant change in the Ppa in the present

Table 1 Respiratory tissue parameters under baseline conditions, during MCh infusion at a dose of $24 \mu \mathrm{g} / \mathrm{kg} / \mathrm{min}$, and their percentage changes in the different groups

\begin{tabular}{ccccccc}
\hline & \multicolumn{2}{c}{$\mathbf{G}\left(\mathbf{c m H}_{\mathbf{2}} \mathbf{O} / \mathbf{l}\right)$} & Change in G & \multicolumn{2}{c}{$\mathbf{H}\left(\mathbf{c m H}_{\mathbf{2}} \mathbf{O} / \mathbf{l}\right)$} & \multicolumn{2}{c}{ Change in H } \\
\cline { 2 - 7 } & Baseline & $\mathbf{M C h ~} \mathbf{2 4} \boldsymbol{\mu g} / \mathbf{k g} / \mathbf{m i n}$ & $\%$ & Baseline & MCh $\mathbf{2 4} \boldsymbol{\mu g} / \mathbf{k g} / \mathbf{m i n}$ & \% \\
\hline CC & $866 \pm 49$ & $1150 \pm 76^{*}$ & $33 \pm 5$ & $2927 \pm 299$ & $3767 \pm 334^{*}$ & $15 \pm 6$ \\
CS & $736 \pm 42$ & $968 \pm 78^{*}$ & $31 \pm 5$ & $2936 \pm 167$ & $3329 \pm 195^{*}$ & $24 \pm 5$ \\
VIP & $735 \pm 33$ & $991 \pm 49^{*}$ & $37 \pm 10$ & $2589 \pm 258$ & $3139 \pm 231^{*}$ & $10 \pm 10$ \\
ILO & $802 \pm 84$ & $930 \pm 65^{*}$ & $21 \pm 9$ & $2972 \pm 397$ & $3061 \pm 147$ & $16 \pm 3$ \\
SIL & $964 \pm 45$ & $1159 \pm 50^{*}$ & $21 \pm 6$ & $3240 \pm 281$ & $3741 \pm 278^{*}$ & $26 \pm 2$ \\
TEZ & $727 \pm 34$ & $911 \pm 58^{*}$ & $25 \pm 3$ & $2370 \pm 156$ & $3001 \pm 232^{*}$ & 2 \\
\hline
\end{tabular}

CC: control group, CS: shunt, no treatments, VIP: shunt, treatment with VIP, ILO: shunt, treatment with iloprost, SIL: shunt, treatment with sildenafil, TEZ: shunt, treatment with tezosentan.

*: $p<0.05$ vs. the value obtained under baseline conditions within a group. 


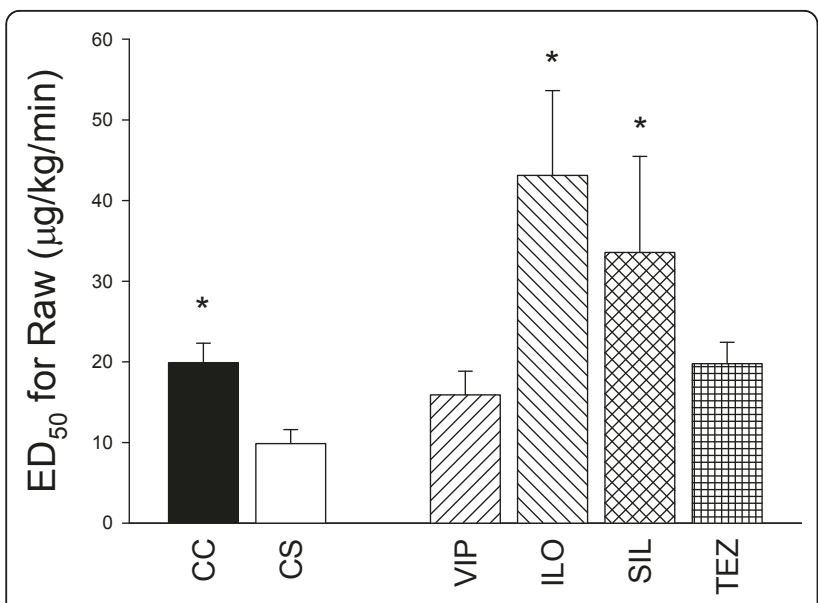

Figure 5 Equivalent dose required to cause a $50 \%$ increase in airway resistance $\left(E D_{50}\right)$ in the different groups. CC: control group, CS: shunt, no treatments, VIP: shunt, treatment with VIP, ILO: shunt, treatment with iloprost, SIL: shunt, treatment with sildenafil, TEZ: shunt, treatment with tezosentan. *: $p<0.05$ vs. the data obtained in the rats with precapillary pulmonary hypertension without drug treatment (Group CS).

study. However, the similar abilities of $\mathrm{ET}_{\mathrm{A}}$ and $\mathrm{ET}_{\mathrm{B}}$ to relax the airway smooth muscle are reflected in the potential of tezosentan to prevent BHR effectively. This raises the unsolved controversy of the use of specific $\mathrm{ET}_{\mathrm{A}}$ or dual blockers: clinical studies have so far failed to reveal significant differences between selective $\mathrm{ET}_{\mathrm{A}}$ and dual receptor blockade [31]. However, our data suggest

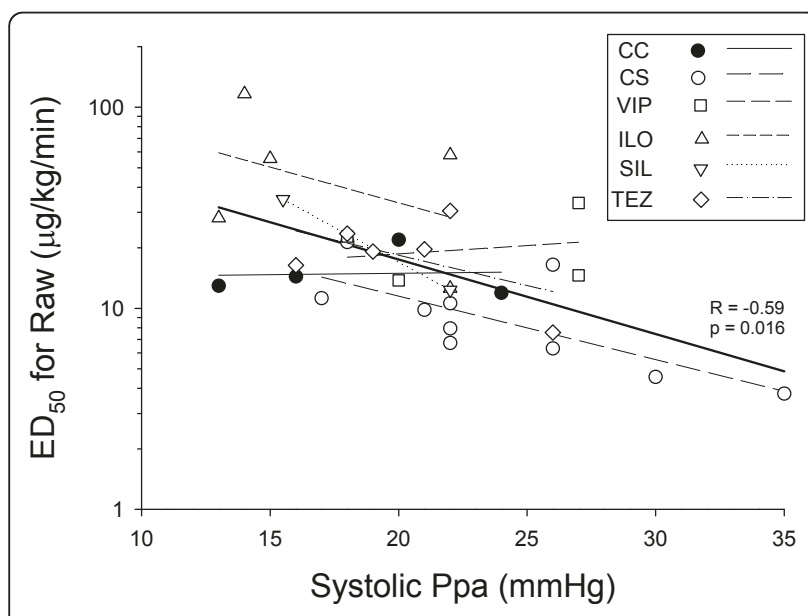

Figure 6 The relationships between the systolic pulmonary arterial pressure (Ppa) and the lung responsiveness expressed as the equivalent dose required to cause a $50 \%$ increase in the airway resistance $\left(E D_{50}\right)$ in the different groups. CC: control group, CS: shunt, no treatments, VIP: shunt, treatment with VIP, ILO: shunt, treatment with iloprost, SIL: shunt, treatment with sildenafil, TEZ: shunt, treatment with tezosentan. Symbols: individual data points in each rat, thin lines: regressions for individual groups, thick line: linear regression for the pooled data. that the detrimental effects of precapillary PHT can be effectively prevented by dual ET-1 receptor blockade.

VIP plays a major role in regulating the smooth muscle tone around both the pulmonary vasculature and the bronchi via the non-adrenergic non-cholinergic nervous system [32-34]. Since VIP exerts its relaxation potential on the smooth muscle by opening $\mathrm{Ca}^{2+}$-activated $\mathrm{K}^{+}$ channels through a cAMP-dependent mechanism $[35,36]$ and by inducing NO release from VIP/NO-containing nerve fibers and the endothelium $[32,37]$, its inhalation has recently been advocated in the treatment of PHT [38,39]. Although previous studies have suggested the efficacy of this peptide in inducing transient pulmonary vasodilation in another model of PHT [39], our findings indicate that the chronic continuous intraperitoneal administration of VIP did not provide a decrease in Ppa in the presence of precapillary PHT. However, BHR was eliminated by VIP treatment, which is in accord with previous results demonstrating its bronchodilation properties [10,40].

\section{Summary and conclusions}

This comparison of treatment strategies aimed at reestablishment of the balance between the various smooth muscle constrictor and relaxation mediators revealed similar abilities of the agonists acting on the PC, NO, ET-1 and VIP pathways to protect the development of airway hyperreactivity subsequent to precapillary PHT. The pathophysiological mechanisms responsible for the fairly uniform bronchial effects of the various treatments may be inferred from the significant correlation between the lung responsiveness and the level of systolic PHT (Figure 6). This close association suggests that independently of the pharmacotherapeutical approach to influence the pulmonary vasculature, it is the level of Ppa which determines the lung responsiveness through the existence of a close mechanical interdependence between the pulmonary vasculature and the airway tree.

\footnotetext{
Acknowledgements

Supported by Hungarian Basic Scientific Research Grant OTKA K81179 and Swiss National Science Foundation Grant SNSF 32003B-118231. Ferenc Petak is supported by a Bolyai Janos Research Fellowship.

The authors are grateful for the excellent technical assistance of Jorge-Costa Manuel.

Vasoactive Intestinal peptide (VIP - Aviptadil) was provided by mondoBIOTECH Holding AG, Switzerland, tezosentan by Actelion Pharmaceuticals Ltd, Allschwil, Switzerland, and iloprost by Bayer (Schweiz) $A G$, Switzerland.
}

\section{Author details}

'Pediatric Anesthesia Unit, Geneva Children's Hospital, University Hospitals of Geneva, 6, Rue Willy Donze, CH-1205, Geneva, Switzerland.

${ }^{2}$ Anesthesiological Investigations Unit, University Hospitals of Geneva, 1 Rue Michel Servet, CH-1205, Geneva, Switzerland. ${ }^{3}$ Pediatric Cardiology Unit, Department of Pediatrics, Geneva Children's Hospital, 6, Rue Willy Donze, $\mathrm{CH}-1205$, Geneva, Switzerland. ${ }^{4}$ Department of Medical Physics and Informatics, University of Szeged, 9 Koranyi fasor, H-6720, Szeged, Hungary. 


\section{Authors' contributions}

WH conducted the design of the study and had a major role in drafting the manuscript. GA and TJ carried out the experiments and the preliminary data analyses. FF performed the surgical preparation and helped in conducting the pretreatments and performing the experiments. BSU participated in the study design, data collection and helped in processing the data. MB participated in the design of the study and interpretation of the experimental findings. FP coordinated the various experimental approaches, contributed in their design and in the manuscript preparation. All authors read and approved the final manuscript.

\section{Competing interests}

The authors declare that they have no competing interests.

Received: 7 December 2010 Accepted: 27 April 2011

Published: 27 April 2011

\section{References}

1. Hoeper MM, Rubin LJ: Update in pulmonary hypertension 2005. Am J Respir Crit Care Med 2006, 173:499-505.

2. McLaughlin W, Genthner DE, Panella MM, Rich S: Reduction in pulmonary vascular resistance with long-term epoprostenol (prostacyclin) therapy in primary pulmonary hypertension. N Engl J Med 1998, 338:273-277.

3. Murali S: Pulmonary arterial hypertension. Curr Opin Crit Care 2006 12:228-234.

4. Rich S: The current treatment of pulmonary arterial hypertension: time to redefine success. Chest 2006, 130:1198-1202.

5. Humbert M, Sitbon O, Simonneau G: Treatment of pulmonary arterial hypertension. N Engl J Med 2004, 351:1425-1436.

6. Howard LS, Morrell NW: New therapeutic agents for pulmonary vascular disease. Paediatr Respir Rev 2005, 6:285-291.

7. Keith IM: The role of endogenous lung neuropeptides in regulation of the pulmonary circulation. Physiol Res 2000, 49:519-537.

8. Habre W, Petak F, Ruchonnet-Metrailler I, Donati Y, Tolsa JF, Lele E, Albu G, Beghetti M, Barazzone-Argiroffo C: The role of endothelin-1 in hyperoxiainduced lung injury in mice. Respir Res 2006, 7:45.

9. Ghofrani HA, Osterloh $\mathrm{H}$, Grimminger F: Sildenafil: from angina to erectile dysfunction to pulmonary hypertension and beyond. Nat Rev Drug Discov 2006, 5:689-702

10. Janosi T, Petak F, Fontao F, Morel DR, Beghetti M, Habre W: Differential roles of endothelin-1 ETA and ETB receptors and vasoactive intestinal polypeptide in regulation of the airways and the pulmonary vasculature in isolated rat lung. Exp Physiol 2008, 93:1210-1219.

11. von Ungern-Sternberg BS, Habre W, Regli A, Pache JC, Fontao F, Janosi TZ, Beghetti M, Petak F: Precapillary pulmonary hypertension leads to reversible bronchial hyperreactivity in rats. Exp Lung Res 2010, 36:129-139.

12. Garcia R, Diebold S: Simple, rapid, and effective method of producing aortocaval shunts in the rat. Cardiovasc Res 1990, 24:430-432.

13. Ocampo C, Ingram P, llbawi M, Arcilla R, Gupta M: Revisiting the surgical creation of volume load by aorto-caval shunt in rats. Mol Cell Biochem 2003, 251:139-143

14. Habre W, Janosi TZ, Fontao F, Meyers C, Albu G, Pache JC, Petak F: Mechanisms for lung function impairment and airway hyperresponsiveness following chronic hypoxia in rats. Am J Physiol Lung Cell Mol Physiol 2010, 298:L607-614.

15. Janosi TZ, Adamicza A, Zosky GR, Asztalos T, Sly PD, Hantos Z: Plethysmographic estimation of thoracic gas volume in apneic mice. J Appl Physiol 2006, 101:454-459.

16. Petak F, Hantos Z, Adamicza A, Asztalos T, Sly PD: Methacholine-induced bronchoconstriction in rats: effects of intravenous vs. aerosol delivery. J Appl Physiol 1997, 82:1479-1487.

17. Petak F, Habre W, Hantos Z, Sly PD, Morel DR: Effects of pulmonary vascular pressures and flow on airway and parenchymal mechanics in isolated rat lungs. J Appl Physiol 2002, 92:169-178.

18. Hantos Z, Daroczy B, Suki B, Nagy S, Fredberg JJ: Input impedance and peripheral inhomogeneity of dog lungs. J Appl Physiol 1992, 72:168-178.

19. Petak F, Hall GL, Sly PD: Repeated measurements of airway and parenchymal mechanics in rats by using low-frequency oscillations. J Appl Physiol 1998, 84:1680-1686.
20. Lam CF, Peterson TE, Croatt AJ, Nath KA, Katusic ZS: Functional adaptation and remodeling of pulmonary artery in flow-induced pulmonary hypertension. Am J Physiol Heart Circ Physiol 2005, 289:H2334-2341.

21. Larsen GL, Loader J, Fratelli C, Kang JK, Dakhama A, Colasurdo GN: Modulation of airway responses by prostaglandins in young and fully grown rabbits. Am J Physiol Lung Cell Mol Physiol 2007, 293:L239-244.

22. Ricciardolo FL, Sterk PJ, Gaston B, Folkerts G: Nitric oxide in health and disease of the respiratory system. Physiol Rev 2004, 84:731-765.

23. Higenbottam TW, Butt AY, Dinh-Xaun AT, Takao M, Cremona G, Akamine S: Treatment of pulmonary hypertension with the continuous infusion of a prostacyclin analogue, iloprost. Heart 1998, 79:175-179.

24. Gomberg-Maitland M, Olschewski H: Prostacyclin therapies for the treatment of pulmonary arterial hypertension. Eur Respir J 2008, 31:891-901.

25. Giaid A, Yanagisawa M, Langleben D, Michel RP, Levy R, Shennib H, Kimura S, Masaki T, Duguid WP, Stewart DJ: Expression of endothelin-1 in the lungs of patients with pulmonary hypertension. N Engl J Med 1993, 328:1732-1739.

26. Galie N, Ghofrani HA, Torbicki A, Barst RJ, Rubin LJ, Badesch D, Fleming T, Parpia T, Burgess G, Branzi A, et al: Sildenafil citrate therapy for pulmonary arterial hypertension. N Engl J Med 2005, 353:2148-2157.

27. Brown RH, Zerhouni EA, Hirshman CA: Reversal of bronchoconstriction by inhaled nitric oxide. Histamine versus methacholine. Am J Respir Crit Care Med 1994, 150:233-237.

28. Hogman M, Frostell C, Arnberg H, Hedenstierna G: Inhalation of nitric oxide modulates methacholine-induced bronchoconstriction in the rabbit. Eur Respir J 1993, 6:177-180.

29. MacLean MR, McCulloch KM, Baird M: Endothelin ETA- and ETB-receptormediated vasoconstriction in rat pulmonary arteries and arterioles. J Cardiovasc Pharmacol 1994, 23:838-845.

30. Leuchte HH, Meis T, El-Nounou M, Michalek J, Behr J: Inhalation of endothelin receptor blockers in pulmonary hypertension. Am J Physiol Lung Cell Mol Physiol 2008, 294:L772-777.

31. Opitz CF, Ewert R, Kirch W, Pittrow D: Inhibition of endothelin receptors in the treatment of pulmonary arterial hypertension: does selectivity matter? Eur Heart J 2008, 29:1936-1948.

32. Anaid S, Petkov V, Baykuscheva-Gentscheva T, Hoeger H, Painsipp E, Holzer P, Mosgoeller W: Involvement of endothelial NO in the dilator effect of VIP on rat isolated pulmonary artery. Regul Pept 2007, 139:102-108.

33. Iwabuchi S, Ono S, Tanita T, Koike K, Fujimura S: Vasoactive intestinal peptide causes nitric oxide-dependent pulmonary vasodilation in isolated rat lung. Respiration 1997, 64:54-58.

34. Crimi N, Palermo F, Oliveri R, Palermo B, Vancheri C, Polosa R, Mistretta A: Effect of vasoactive intestinal peptide (VIP) on propranolol-induced bronchoconstriction. J Allergy Clin Immunol 1988, 82:617-621.

35. Hagen BM, Bayguinov O, Sanders KM: VIP and PACAP regulate localized $\mathrm{Ca} 2+$ transients via cAMP-dependent mechanism. Am J Physiol Cell Physiol 2006, 291:C375-385.

36. Kishi M, Takeuchi T, Suthamnatpong N, Ishii T, Nishio H, Hata F, Takewaki T: VIP- and PACAP-mediated nonadrenergic, noncholinergic inhibition in longitudinal muscle of rat distal colon: involvement of activation of charybdotoxin- and apamin-sensitive K+ channels. Br J Pharmacol 1996, 119:623-630.

37. Lee TJ: Nitric oxide and the cerebral vascular function. J Biomed Sci 2000, 7:16-26.

38. Petkov V, Mosgoeller W, Ziesche R, Raderer M, Stiebellehner L, Vonbank K, Funk GC, Hamilton G, Novotny C, Burian B, Block LH: Vasoactive intestinal peptide as a new drug for treatment of primary pulmonary hypertension. J Clin Invest 2003, 111:1339-1346.

39. Leuchte HH, Baezner C, Baumgartner RA, Bevec D, Bacher G, Neurohr C, Behr J: Inhalation of vasoactive intestinal peptide in pulmonary hypertension. Eur Respir J 2008, 32:1289-1294.

40. Barnes PJ, Dixon CM: The effect of inhaled vasoactive intestinal peptide on bronchial reactivity to histamine in humans. Am Rev Respir Dis 1984, 130:162-166

doi:10.1186/1465-9921-12-58

Cite this article as: Habre et al:: Prevention of bronchial hyperreactivity in a rat model of precapillary pulmonary hypertension. Respiratory Research 2011 12:58. 